\title{
Diminished Insulin-Mediated Forearm Blood Flow and Muscle Glucose Uptake in Young Men with Low Birth Weight
}

\author{
M.P.Sonne ${ }^{a} \quad$ L. Højbjerre ${ }^{a} \quad$ A.C. Alibegovic ${ }^{b} \quad$ A. Vaag $^{b} \quad$ B. Stallknecht ${ }^{a} \quad$ F. Dela ${ }^{a}$

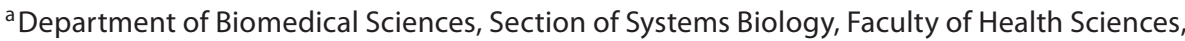 \\ University of Copenhagen, Copenhagen, and ${ }^{b}$ Steno Diabetes Centre, Gentofte, Denmark
}

\section{Key Words}

Acetylcholine - Adenosine - Endothelial function • Insulin • Insulin sensitivity

\begin{abstract}
Background: Low birth weight (LBW) is associated with increased risk of type 2 diabetes and cardiovascular disease. We studied endothelial function and insulin sensitivity in young men with LBW $(n=22)$ and controls $(n=22)$. Methods: Insulin sensitivity and endothelial function was studied with venous occlusion plethysmography and intra-arterial infusions of adenosine and acetylcholine, before and during a hyperinsulinemic isoglycemic clamp. Results: Forearm blood flow response to systemic hyperinsulinemia was diminished in LBW compared to controls $(p<0.05)$. Fractional arteriovenous glucose extraction was similar, and consequently insulin-stimulated forearm glucose clearance was diminished in LBW compared with controls $(0.8 \pm 0.09$ vs. $1.4 \pm 0.36 \mathrm{ml} \cdot 100 \mathrm{ml}^{-1} \cdot \mathrm{min}^{-1}$, respectively, $\left.\mathrm{p}<0.05\right)$. Forearm blood flow response to adenosine and acetylcholine with or without insulin stimulation did not differ between groups. Whole-body glucose uptake was lower in LBW than controls $\left(8.7 \pm 0.5\right.$ and $9.1 \pm 0.6 \mathrm{mg} \cdot \mathrm{min}^{-1} \cdot \mathrm{kg}^{-1}$ lean body mass); however, this was not significant. Conclusions: Forearm blood flow response to insulin is impaired in LBW,
\end{abstract}

whereas the response to adenosine and acetylcholine is preserved. The impaired insulin-mediated increase in bulk flow in LBW may be due to an impairment of insulin-mediated capillary recruitment independent of - or preceding whole-body insulin resistance in LBW subjects.

Copyright $\odot 2009$ S. Karger AG, Basel

\section{Introduction}

Lifestyle factors and genetic predisposition play a significant role in the lifetime risk of developing insulin resistance and cardiovascular disease. Furthermore, according to the theory of fetal origin of diseases [1], humans born with a low birth weight (LBW) for gestational age have an increased risk of developing these conditions. In LBW, discrete abnormalities in glucose and fat metabolism have been reported [2-5] and, moreover, there is also an association with LBW and increased incidence of hypertension and cardiovascular disease in later adult life $[6,7]$.

It is controversial if LBW is also associated with endothelial dysfunction [8-12]. In studies $[8,10,11]$ that have reported endothelial dysfunction in LBW, endothelial function has been estimated by measurements of flowmediated brachial artery dilation (examining the conduit

\section{KARGER}

Fax +41613061234 E-Mail karger@karger.ch www.karger.com
(C) 2009 S. Karger AG, Basel

$1018-1172 / 10 / 0472-0139 \$ 26.00 / 0$

Accessible online at:

www.karger.com/jvr
Dr. Mette Paulli Sonne

Department of Biomedical Sciences, Section of Systems Biology

Faculty of Health Sciences, University of Copenhagen

Blegdamsvej 3 B, DK-2200 Copenhagen N (Denmark)

Tel. +45 3532 7413, Fax + 453532 7420,E-Mail msonne@mfi.ku.dk 
vessels). However, in studies $[9,12]$ where intra-arterial infusion of endothelium-dependent vasodilators [e.g. acetylcholine $(\mathrm{ACH})]$ was used to examine the resistance vessels, no difference between LBW and controls (CON) was found.

Adenosine (ADN) is a partly endothelial-dependent vasodilator $[13,14]$; however, peripheral vasoactivity in response to $\mathrm{ADN}$ has not, to our knowledge, been measured in healthy LBW and appropriate control subjects before. Reduced coronary artery blood flow response to $\mathrm{ADN}$ is associated with insulin resistance [15], and hyperinsulinemia potentiates the vasodilatation response of ADN in the coronary arteries of healthy subjects [16].

Insulin stimulates bulk flow and capillary recruitment via endothelial dependent pathways [17, 18], and an intact vascular insulin response is obligatory for an optimal metabolic insulin response $[17,19,20]$. The vascular insulin response in LBW to systemic insulin infusion has, to our knowledge, not been examined before. Therefore, the aim of this study was to characterize the blood flow responses to insulin, $\mathrm{ACH}$ and $\mathrm{ADN}$, and to measure insulin-mediated glucose uptake rates in whole body and in the forearm (primarily representing skeletal muscle) in subjects with LBW during steady-state conditions. We performed a hyperinsulinemic, isoglycemic clamp in combination with a-v catheterization of the forearm, allowing pharmacological stimulation of forearm blood flow before and during systemic hyperinsulinemia. In accordance with observations in obese subjects [21,22], decreased vascular insulin sensitivity could be present in LBW, which in turn could contribute to metabolic insulin resistance.

\section{Subjects and Methods}

\section{Subjects}

We recruited 44 healthy, white, male subjects born at term [gestational week $40 \pm 0.2$ and $40 \pm 0.1$ weeks in LBW and CON, respectively $(\mathrm{p}>0.05)]$ via the Danish Birth Registry. Twenty-two were born with LBW ( $<10$ percentile: birth weight 2,530 $\pm 50 \mathrm{~g}$ ) and 22 were CON subjects, born with normal birth weight (50-75 percentile: birth weight $3,797 \pm 49$ g; $\mathrm{p}<0.001$, LBW vs. CON). The 2 groups were matched groupwise according to age, BMI and physical fitness (table 1). Body composition was determined by Dexa scanning (Lunar Prodigy Advance; GE Healthcare, USA). $\mathrm{VO}_{2 \max }$ was measured on a bicycle ergometer with a stepwise incremental test using the leveling off criterion (Oxycon Pro; Jaeger Instruments, Höchberg, Germany).

None of the subjects had a family history of type 2 diabetes. Six subjects had 1 first-degree relative with hypertension. Two subjects were smokers (15 cigarettes per day, 1 subject in each group).
Table 1. Basal characteristics

\begin{tabular}{|c|c|c|}
\hline & $\begin{array}{l}\text { CON } \\
(\mathrm{n}=22)\end{array}$ & $\begin{array}{l}\text { LBW } \\
(\mathrm{n}=22)\end{array}$ \\
\hline Age, years & $25 \pm 0.2$ & $26 \pm 0.5$ \\
\hline Height, m & $1.85 \pm 0.01$ & $1.79 \pm 0.01^{*}$ \\
\hline Weight, kg & $83 \pm 2$ & $75 \pm 3^{*}$ \\
\hline BMI, $\mathrm{kg} / \mathrm{m}^{2}$ & $24 \pm 1$ & $23 \pm 1$ \\
\hline Body fat, \% & $18.6 \pm 1.7$ & $19.7 \pm 1.4$ \\
\hline Waist-to-hip ratio & $0.86 \pm 0.005$ & $0.87 \pm 0.06$ \\
\hline $\mathrm{V}_{\mathrm{o}_{2 \max }}, \mathrm{ml} / \mathrm{min} / \mathrm{kg}$ & $43.5 \pm 1.3$ & $42.6 \pm 2.7$ \\
\hline Systolic blood pressure, $\mathrm{mm} \mathrm{Hg}$ & $128 \pm 2$ & $126 \pm 4$ \\
\hline Diastolic blood pressure, $\mathrm{mm} \mathrm{Hg}$ & $69 \pm 2$ & $69 \pm 3$ \\
\hline Glucose, $\mathrm{mmol} / \mathrm{l}$ & $5.3 \pm 0.06$ & $5.4 \pm 0.07$ \\
\hline Insulin, pM & $35 \pm 3$ & $38 \pm 5$ \\
\hline C-peptide, pM & $513 \pm 25$ & $531 \pm 42$ \\
\hline HbA1C, \% & $5.1 \pm 0.1$ & $5.1 \pm 0.1$ \\
\hline Total cholesterol, mmol/l & $3.9 \pm 0.2$ & $4.1 \pm 0.2$ \\
\hline $\mathrm{HDL}, \mathrm{mmol} / \mathrm{l}$ & $1.3 \pm 0.1$ & $1.3 \pm 0.1$ \\
\hline LDL, mmol/l & $2.2 \pm 0.1$ & $2.3 \pm 0.2$ \\
\hline Triglyceride, mmol/l & $0.9 \pm 0.1$ & $1.1 \pm 0.2$ \\
\hline Homocysteine, $\mu \mathrm{mol} / \mathrm{l}$ & $9.8 \pm 0.5$ & $11.1 \pm 0.2$ \\
\hline hsCRP, nmol/l & $25.1 \pm 6.6$ & $27.5 \pm 8.4$ \\
\hline ICAM, ng/ml & $227 \pm 8$ & $217 \pm 11$ \\
\hline VCAM, ng/ml & $610 \pm 19$ & $593 \pm 38$ \\
\hline von Willebrand factor, Kiu/l & $0.90 \pm 0.07$ & $0.86 \pm 0.05$ \\
\hline
\end{tabular}

All values are means \pm SEM. All blood samples were obtained after an overnight fast. Glucose is arterial blood.

${ }^{*} \mathrm{p}<0.05, \mathrm{LBW}$ vs. CON.

The study was approved by the regional ethics committee [No. (01) 262546] and all procedures were performed in accordance with the guidelines of the Declaration of Helsinki. Informed written consent was obtained from all subjects before participation.

Experimental Protocol

All subjects were provided with a standardized isocaloric nutritionally recommended diet (55 E\% of carbohydrates, $15 \mathrm{E} \%$ of protein, and $30 \mathrm{E} \%$ of fat) 4 days prior to the study. After $10 \mathrm{~h}$ overnight fasting, the subjects reported to the laboratory. Electrocardiogram and heart rate were monitored by precordial electrodes. Arterial catheters (Becton Dickinson, UK) were inserted in the brachial arteries of both arms for blood sampling (control arm), blood pressure monitoring (control arm) and for infusion of vasodilators (intervention arm). Venous catheters (18 G Venflon; Medex Medicine, UK) were inserted in the medial antecubital veins of both arms. In the intervention arm they were inserted in a retrograde direction (for blood sampling) and in the control arm they were antegrade (for infusion of insulin and glucose). In 3 CON and 1 LBW subjects, $1(n=3)$ or both $(n=1)$ arterial lines could not be inserted, and arterialized blood samples from a heated hand vein were used as replacement. In $5 \mathrm{CON}$ subjects and $1 \mathrm{LBW}$ subject, it was not possible to insert the retrograde venous catheter. 


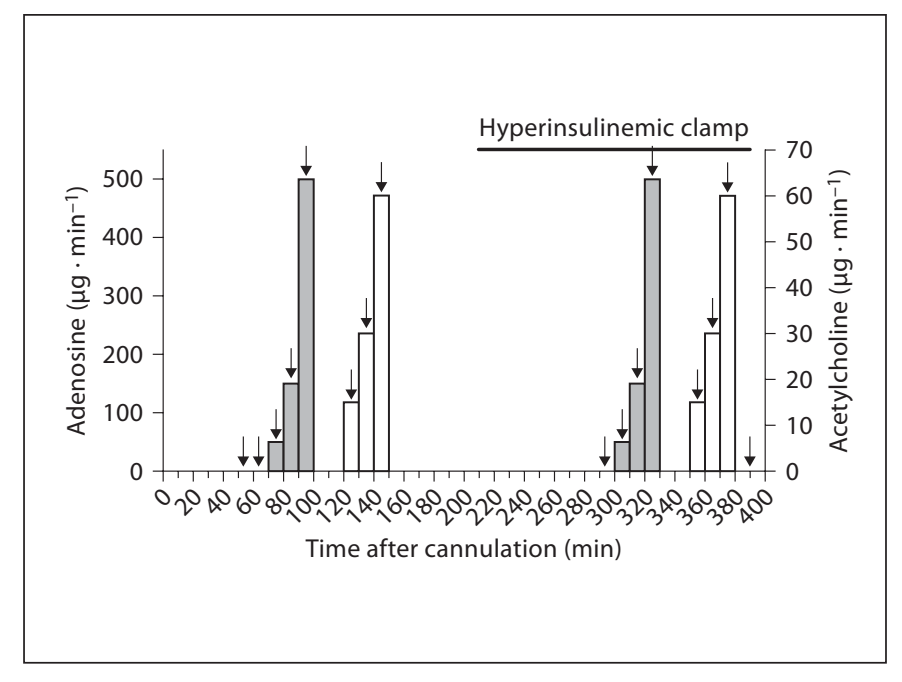

Fig. 1. Protocol for the experiment. The $\mathrm{x}$-axis is time after insertion of arterial and venous catheters. Shaded columns are intraarterial infusions of ADN (left y-axis) and white columns are intra-arterial infusions of $\mathrm{ACH}$ (right y-axis). The arrows indicate forearm blood flow measurement by venous occlusion plethysmography and arteriovenous blood was sampled.

We measured forearm blood flow (FBF) simultaneously in both arms by venous occlusion mercury-in-Silastic strain-gauge plethysmography (Hokanson EC6 and E20; Marcom, Vemmelev, Denmark). Blood flow was measured at cycles of $7 \mathrm{~s}$ and calculated as an average of 5-7 consecutive readings. Around the wrists small cuffs were positioned and inflated to suprasystolic pressures during plethysmography recordings and blood sampling, in order to exclude the circulation of the hand and the contribution of the a-v shunts, respectively. All measurements and analyses were carried out by a single investigator (M.S.).

Time points for the infusion regimen of vasodilators are shown in figure 1 . ADN was infused intra-arterially in three 5-min intervals at each rate (see below). At the end of each interval, FBF were measured and arteriovenous blood sampled. When blood flow had returned to baseline values, the intra-arterial infusions commenced with infusions of $\mathrm{ACH}$. At $\mathrm{t}=210 \mathrm{~min}$, the clamp was started. At $t=300 \mathrm{~min}$ (90 min after start of the insulin infusion), the intra-arterial infusion regimen with $\mathrm{ADN}$ and $\mathrm{ACH}$ infusions was repeated.

\section{Calculations}

Glucose infusion rates were averaged for 10 -min periods (fig. 2) and whole-body insulin-mediated glucose uptake rates were calculated as the mean of steady-state glucose infusion rates during the last $30 \mathrm{~min}$ of the clamp $(\mathrm{t}=150-180 \mathrm{~min}$ clamp time; $\mathrm{M}$-value). Baseline FBF and a-v differences were measured at $\mathrm{t}=$ $60 \mathrm{~min}$, just before the start of the infusions. Clamp FBF and a-v differences were measured at $\mathrm{t}=300 \mathrm{~min}$ (clamp time $90 \mathrm{~min}$ ) and at $\mathrm{t}=390 \mathrm{~min}$ (clamp time $180 \mathrm{~min}$ ). There was no significant difference between flow and forearm fractional glucose extraction at the 2 latter time points, thus an average of these time points was used.

Insulin Action in Young Men with Low Birth Weight

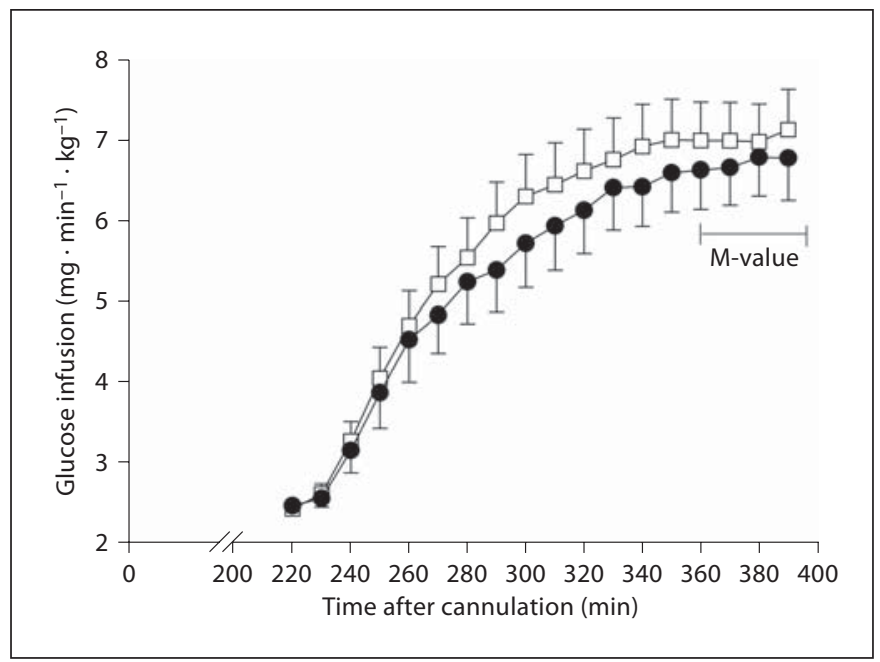

Fig. 2. Glucose infusion rates averaged for periods of $10 \mathrm{~min}$ in 22 subjects born with LBW (circles) and 22 CON subjects (squares) during a 3-hour hyperinsulinemic, isoglycemic clamp. No significant difference between the glucose infusion rates in the 2 groups was observed. Values are means \pm SEM.

Fractional glucose extraction across the intervention arm (forearm) was calculated as the a-v difference divided by the arterial glucose concentration and expressed in percent. Glucose clearance (intervention arm) was calculated as glucose extraction multiplied by the FBF (expressed as $\mathrm{ml} \cdot 100 \mathrm{ml}^{-1} \cdot \mathrm{min}^{-1}$ ) and glucose uptake was calculated as glucose a-v difference multiplied by the FBF (expressed as $\mathrm{mg} \cdot \mathrm{kg}^{-1} \cdot \mathrm{min}^{-1}$ ).

Forearm vascular conductance was calculated as FBF divided by mean arterial pressure (MAP) and expressed as $\mathrm{ml} \cdot 100 \mathrm{ml}^{-1}$. $\mathrm{min}^{-1} \cdot \mathrm{mm} \mathrm{Hg}^{-1}$.

Respiratory coefficient across the forearm was calculated as carbon dioxide production over the forearm ( $\mathrm{v}-\mathrm{a}$ ) divided by oxygen consumption (a-v).

\section{Infusates and Infusion Regimens}

$\mathrm{ADN}$ and $\mathrm{ACH}$ solutions were prepared from stock solutions (5 $\mathrm{mg} \cdot \mathrm{ml}^{-1}$; Item Development AB, Stocksund, Sweden, and Michol-E $10 \mathrm{mg} \cdot \mathrm{ml}^{-1}$; Novartis Pharma AG, Basel, Switzerland, respectively) and isotonic sodium chloride. Intra-arterial infusion rates were 50,150 and $500 \mu \mathrm{g} \cdot \mathrm{min}^{-1}(\mathrm{ADN})$ and 15,30 and 60 $\mu \mathrm{g} \cdot \mathrm{min}^{-1}(\mathrm{ACH})$.

For the hyperinsulinemic isoglycemic clamp, a $50-\mathrm{ml}$ insulin solution was prepared from insulin (Actrapid $100 \mathrm{U} \cdot \mathrm{ml}^{-1}$; Novo Nordisk, Copenhagen, Denmark), saline, and $2.5 \mathrm{ml}$ of the subject's own plasma and administered as a $2-\mathrm{ml}$ bolus followed by a constant intravenous infusion $\left[40 \mathrm{mU} \cdot \mathrm{min}^{-1} \cdot \mathrm{m}^{2}(-1)\right]$. Arterial blood was sampled every 5-10 min and glucose (20\%) infusion rates were adjusted accordingly. Potassium level was measured throughout the clamp and oral supplements (750 mg Kaleorid; LEO Pharma A/S, Ballerup, Denmark) were given if necessary. The coefficient of variation for the clamps performed in this study was $4.1 \%$. 


\section{Biochemical Analyses}

Plasma concentrations of glucose, potassium and blood gases were analyzed on an automatic analyzer (ABL 735; Radiometer, Copenhagen, Denmark). Concentrations of insulin and C-peptide in plasma were measured with commercially available kits (Dako ELISA, UK). Glycosylated haemoglobin (HbA1C) was measured by high-performance liquid chromatography on a BioRad Variant ${ }^{\mathrm{TM}}$ (Bio-Rad Laboratories, Hercules, Calif., USA). Total cholesterol and HDL-cholesterol was analyzed with an enzymatic colorimetric test (Roche Diagnostic, Mannheim, Germany). LDL cholesterol was calculated from the Friedewald formula [23] and VLDL cholesterol was calculated as triglycerides divided by 2.2. Plasma triglyceride concentration was determined with Triglyceride GPO-PAP (Roche Diagnostic). HsCRP was measured with a 912 Automatic Analyzer (Hitachi, Boehringer, Mannheim, Germany). Homocysteine was measured with reagent Axis-Shield Enzymatic Homocysteine FHER100 on Thermo Konelab 30i, Software version 6.5.h. ICAM-1 and VCAM-1 were analyzed by commercially available kits (ELISA Immunoassay; R\&D Systems, Minneapolis, Minn., USA). Von Willebrand factor (vWF) was analyzed by ELISA at the department of biochemistry at Rigshospitalet, Copenhagen, Denmark.

\section{Statistics}

Statistical analysis was performed using Sigma Stat version 3.1. Student's t test or a nonparametric Mann-Whitney test was used when analyzing data on single measurements, depending on whether data were normally distributed or not. ANOVA for repeated measures was used when analyzing continuous variables. A p value of $<0.05$ was considered significant in 2 -tailed testing. All data are reported as mean \pm SEM. If there were missing data points in the ANOVA analysis a general linear approach (the adjusted sums of squares) was used. Only complete data sets are reported.

Several parameters may be used in power calculations; however, the main objectives were the vascular responses to vasodilators. Power was calculated to above $80 \%$ to detect a $15 \%$ difference between the groups in blood flow response to insulin at the level of $5 \%$ significance.

\section{Results}

Subject characteristics are outlined in table 1. Generally LBW were proportionally smaller than CON (e.g. lower height and weight), but with the same relation between lean body and fat mass. All other parameters including lipid profile were similar.

\section{Response to Insulin}

With insulin infusion, plasma insulin concentration increased to $294 \pm 10$ and $309 \pm 16 \mathrm{pmol} \cdot \mathrm{l}^{-1}$ in $\mathrm{CON}$ and LBW, respectively. The $\mathrm{M}$-value was not different between CON and LBW (7.0 \pm 0.5 and $6.8 \pm 0.5 \mathrm{mg} \cdot$ $\min ^{-1} \cdot \mathrm{kg}$ body weight ${ }^{-1}$; fig. 2). When expressed relative to lean body mass, the M-value also did not differ be-

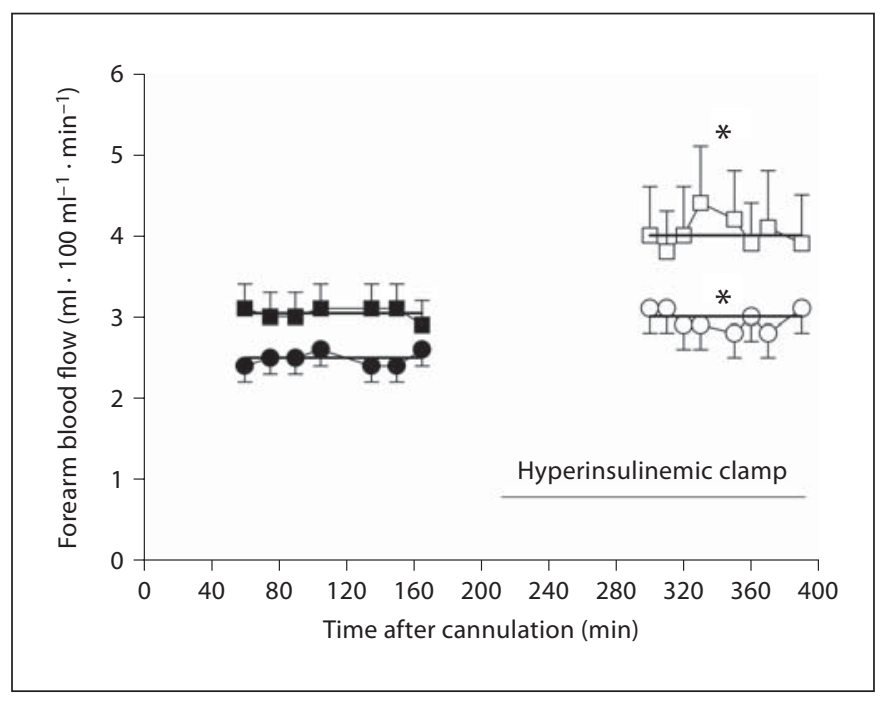

Fig. 3. Forearm blood flow in the control arm of 22 subjects born with LBW (circles) and $22 \mathrm{CON}$ (squares) subjects. Measurements were done by venous occlusion plethysmography. Measurements were done in the basal period (closed symbols) and during insulin infusion (open symbols). In both groups forearm blood flow increased significantly in response to insulin. ${ }^{*} p<0.05$. For difference in forearm blood flow under insulin infusion between the 2 groups: $\mathrm{p}=0.110$. Values are means \pm SEM.

tween groups $\left(9.1 \pm 0.6\right.$ and $8.7 \pm 0.5 \mathrm{mg} \cdot \mathrm{min}^{-1} \cdot \mathrm{kg}$ lean body mass $^{-1}$ in CON and LBW, respectively). The experimental design allowed for simultaneous evaluation of the FBF response to systemic hyperinsulinemia in both arms (intervention arm and control arm). In general, the FBF response was comparable in the 2 arms but different between the groups. In CON and LBW subjects, FBF increased significantly in both arms in response to insulin. (fig. 3, 4). However, the insulin-stimulated FBF was lower in LBW compared to CON subjects $(\mathrm{p}<0.05$ and $\mathrm{p}=0.110$ in intervention and control arm, respectively).

Fractional glucose extraction across the forearm increased by a factor 3-4 in both groups with insulin infusion ( $\mathrm{p}<0.05$ for both groups), but remained similar between the groups (fig. 4). Consequently, forearm glucose clearance rates were similar at baseline but higher $(\mathrm{p}<$ 0.05) in CON during insulin infusion (fig. 4).

In both CON and LBW we found an increase in forearm respiratory coefficient from baseline to insulin stimulation (CON from $0.67 \pm 0.09$ to $0.78 \pm 0.04, \mathrm{p}<0.05$; LBW from $0.61 \pm 0.05$ to $0.75 \pm 0.04, \mathrm{p}<0.05)$. The increase from baseline to insulin stimulation was not different between the groups. 


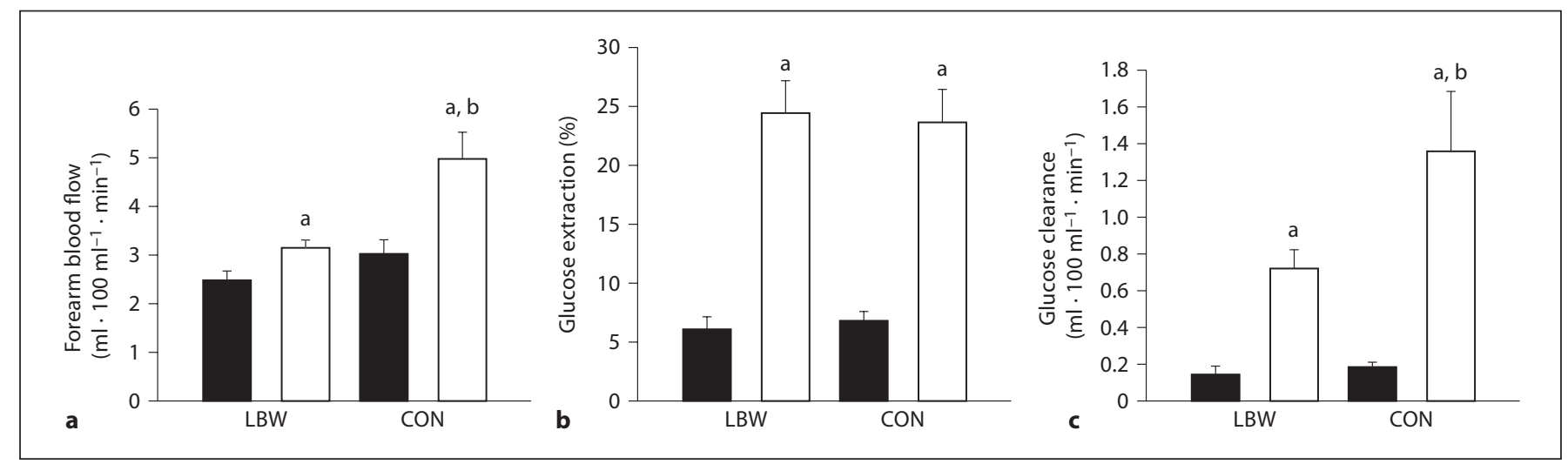

Fig. 4. a FBF in the intervention arm in 22 subjects born with LBW and 22 CON subjects. b Arteriovenous glucose extraction fraction, calculated as $[(\mathrm{a}-\mathrm{v}) / \mathrm{a}] \times 100$, in $20 \mathrm{LBW}$ and $15 \mathrm{CON}$. c Forearm glucose clearance rates $(\mathrm{FBF} \times$ glucose extraction) in 20 LBW and 15 CON. Baseline values (black bars) were obtained

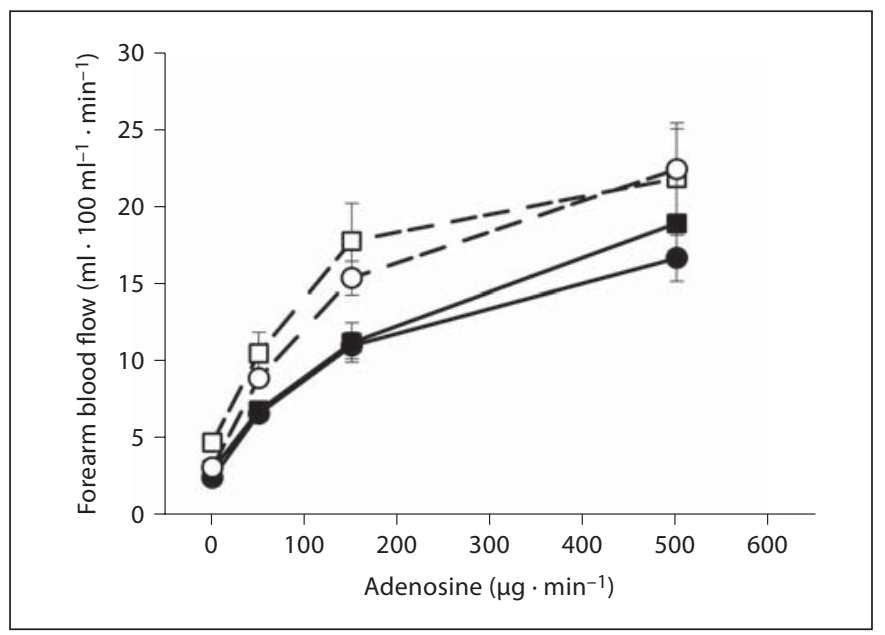

Fig. 5. ADN-induced increase in FBF in 22 subjects born with LBW (circles) and 21 CON subjects (squares). The infusion protocol was repeated during insulin infusion (open symbols and dashed lines). Insulin added significantly $(p<0.05)$ to the effect of ADN stimulation of FBF in both groups. Values are means \pm SEM.

Vasodilator Response and Inflammatory Markers

Average MAP at baseline (CON $86 \pm 1 \mathrm{~mm} \mathrm{Hg}$, LBW $86 \pm 2 \mathrm{~mm} \mathrm{Hg}$ ) compared with average MAP during hyperinsulinemia (CON $85 \pm 2 \mathrm{~mm} \mathrm{Hg}$, LBW $87 \pm 2 \mathrm{~mm}$ $\mathrm{Hg}$ ) was not different in either group nor was there any difference in MAP between the groups.

In response to intra-arterial infusion of $\mathrm{ADN}, \mathrm{FBF}$ increased dose-dependently $(p<0.001)$ and similarly $(p>$ before infusion of vasodilators or insulin (see fig. 1). During insulin infusion, measurements were done a $\mathrm{t}=300 \mathrm{~min}(90 \mathrm{~min}$ into the clamp) and at $\mathrm{t}=390$ (180 min into the clamp) (white bars). ${ }^{a} \mathrm{p}<0.05$ vs. baseline. ${ }^{\mathrm{b}} \mathrm{p}<0.05$, LBW vs. CON. Values are means \pm SEM.

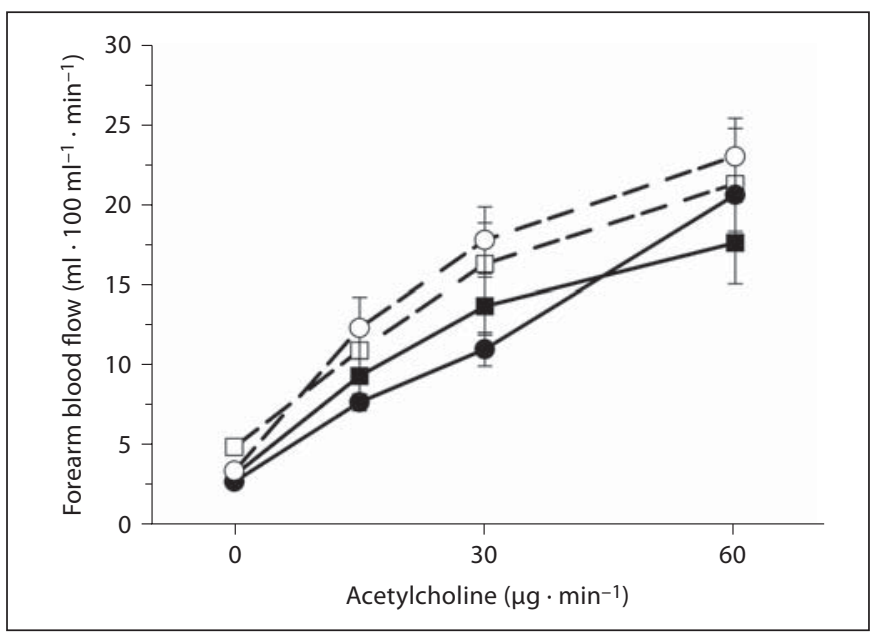

Fig. 6. $\mathrm{ACH}$-induced increase in $\mathrm{FBF}$ in 22 subjects born with LBW (circles) and $21 \mathrm{CON}$ subjects (squares). The infusion protocol was repeated during insulin infusion (open symbols and dashed lines). Insulin added significantly $(p<0.05)$ to the effect of ACH stimulation of FBF in LBW but not in CON ( $p=0.18$ ). Values are means \pm SEM.

0.05 ) in both groups (fig. 5). With the addition of insulin, the FBF response to ADN significantly increased compared with $\mathrm{ADN}$ infusion alone (average increase CON $28 \pm 7 \%$, LBW $27 \pm 1 \%$; fig. 5).

In response to intra-arterial infusion of $\mathrm{ACH}, \mathrm{FBF}$ increased dose-dependently $(\mathrm{p}<0.001)$ and similarly $(\mathrm{p}>$ 0.05 ) in both groups (fig. 6). With the addition of insulin, FBF response to $\mathrm{ACH}$ increased on average by $29 \pm 9 \%$ 


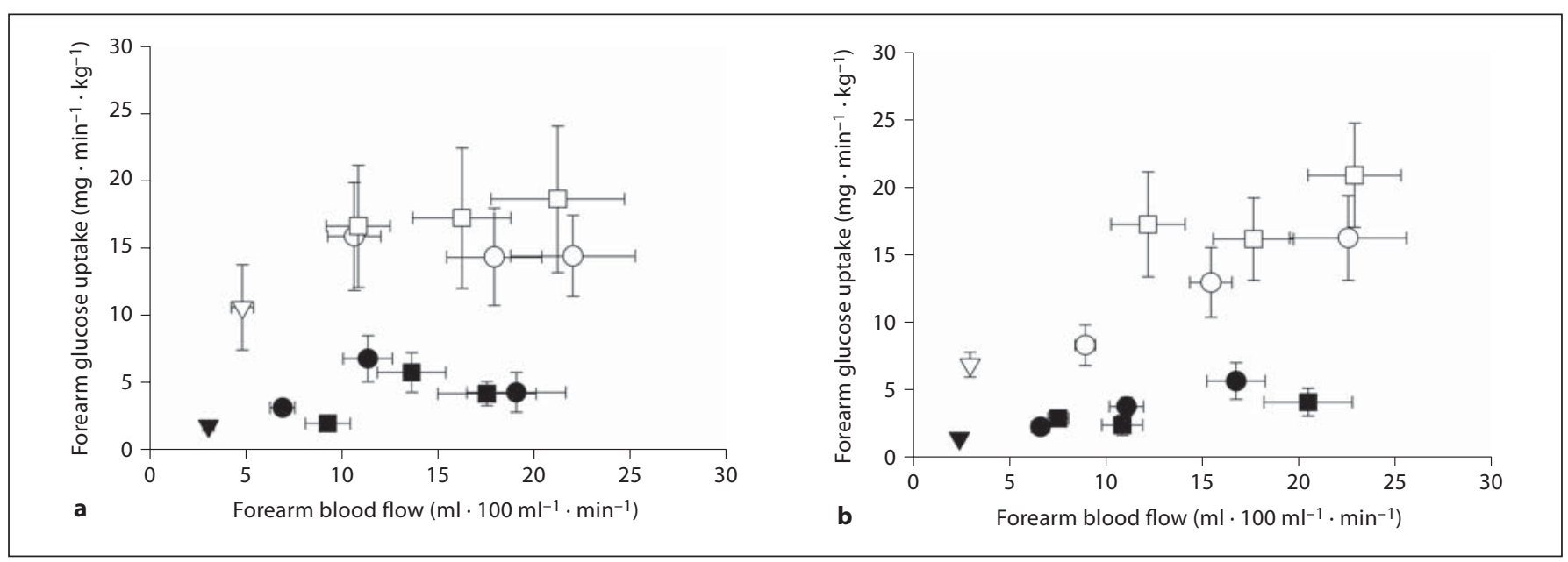

Fig. 7. Forearm glucose uptake vs. forearm blood flow in CON (a) and LBW (b) during $\mathrm{ADN}$ (circles) and $\mathrm{ACH}$ infusions (squares) with (open symbols) and without (closed symbols) hyperinsulinemia. Closed and open triangular symbols refer to baseline data with and without concomitant hyperinsulinemia, respectively [corresponding to time points $295 \mathrm{~min}$ and 55-65 min after cannulation, respectively (see fig. 1)]. Values are means \pm SEM.

ance was lower in LBW compared with CON, while insulin-stimulated whole-body glucose uptake was normal.

To our knowledge, it has not previously been shown that FBF response to systemic hyperinsulinemia is impaired in young healthy LBW subjects. In contrast to the present study, FBF response to insulin has, in fact, previously been shown to be similar in LBW and CON subjects [9]. However, in the previous study local intra-arterial insulin infusion for 20 minutes was used and this could probably explain why the difference in flow responses was not found [9]. Insulin has a slow vasodilatation onset effect on the bulk flow. In the present study, steady-state blood flow measurements were carried out at 90 and 180 min of systemic hyperinsulinemia, at a time when steadystate glucose homeostasis prevailed. Furthermore, lack of blood flow response to local hyperinsulinemia, as opposed to systemic hyperinsulinemia, has previously been noted [24]. Our finding of increased respiratory coefficient across the forearm with insulin stimulation verifies that metabolic rate did increase, but to the same extent in the 2 groups. We cannot exclude the possibility that other known (e.g. insulin-mediated release of ADN and/or ATP from platelets [25]) or unknown vasoactive substances released from LBW and CON in a differential manner due to different glucose utilization rates may explain the differences in blood flow. But, altogether, the data does not support the notion that differences in metabolic rate from the forearm muscles controlled the insulin-stimulated FBF. 
The set of data allows for an evaluation of forearm glucose uptake rates when the FBF is otherwise increased (i.e. by intra-arterial infusion of $\mathrm{ADN}$ or $\mathrm{ACH}$; fig. 7). Whether or not hyperinsulinemia is present, increasing FBF to values above approximately $10 \mathrm{ml} \cdot 100 \mathrm{ml}^{-1}$. $\mathrm{min}^{-1}$ does not result in a further increase in glucose uptake rates. Thus, increased glucose delivery to the forearm muscles above a certain threshold is under these conditions counteracted by a decrease in extraction of glucose from the blood. The role of blood flow in the regulation of muscle glucose uptake has been detailed elsewhere [26].

We did not measure insulin-mediated capillary recruitment in the present study, but others have found a positive association between impaired post-ischemic capillary recruitment in the skin and LBW in children [27] and in adults [28]. Additionally, in 3 months the cutaneous maximal hyperemic response of old LBW infants was found to be impaired, whereas the cutaneous endothelial-dependent vasodilatation was not affected [29]. In neither of these aforementioned studies was macrovessel endothelial function addressed, wherefore a possible association between the conditions of the macrovessels and microvessels in LBW remains unknown. However, our data of impaired forearm insulin-mediated blood flow and normal forearm glucose extraction leading to decreased forearm glucose clearance could be the consequence of capillary recruitment impairment.

A similar whole-body insulin-stimulated glucose uptake (M-value) in LBW and CON subjects has been demonstrated before in subjects who where comparable to the subjects used in the present study [9]. We cannot completely discharge an effect of differences between LBW and CON subjects in hepatic glucose production, which we did not measure. However, in a previous study, it was shown that LBW had a greater suppression of hepatic glucose production compared with CON subjects [30]. If this finding is extrapolated to the present study, our conclusion that insulin-mediated whole-body glucose uptake rates are not decreased in LBW subjects may be somewhat weakened.

The apparent discrepancy of a lower forearm glucose clearance in LBW in the face of a normal whole-body insulin-stimulated glucose uptake has several possible explanations. The differences cannot be attributed to differences in forearm composition. The relationship between arm fat mass and arm lean mass did not differ between groups $(0.18 \pm 0.02$ vs. $0.19 \pm 0.02$ in LBW and CON, respectively, $\mathrm{p}>0.05)$. The forearm constitutes only a small part of the whole-body skeletal muscle mass and therefore a decreased glucose clearance of the forearm could be compensated for by a slightly higher glucose uptake rate in the rest of the skeletal muscles (or adipose tissue). Additionally, the insulin sensitivity in the forearm skeletal muscle may not be fully representative of the entire skeletal muscle in the body [31]. However, the possibility remains that insulin-stimulated glucose uptake is reduced in other skeletal muscle groups to the same extent as in the forearm muscle, and we therefore cannot exclude that increased glucose uptake in nonmuscle tissue, including liver and adipose tissue, may counterbalance reduced muscle glucose uptake in LBW subjects.

In accordance with the present study, a divergent response of insulin on vessel vasodilatation and on wholebody glucose uptake rates was previously found in a study in patients with mild hypertension [32] in which the coronary vasoreactivity to insulin was blunted, but wholebody glucose uptake rates were normal. Thus, it seems that vascular insulin resistance precedes, or can exist without, metabolic insulin resistance. The finding of an impaired insulin vasoreactivity in patients with mild hypertension [32] is intriguing because it is well documented $[33,34]$ that LBW later in life is associated with an increased risk of cardiovascular disease including hypertension.

We found no difference in the vasodilator responses to $\mathrm{ACH}$ and $\mathrm{ADN}$ between $\mathrm{CON}$ and LBW. The ACH data are in accordance with other published data on the forearm $[9,12]$, but the response to $\mathrm{ADN}$ is a novel finding. The facilitating effect of insulin on the endothelium-dependent vasodilator responses as demonstrated in other studies $[9,35]$ was also found in LBW. This may at a first glance seem contradictory due to the impaired effect in LBW of insulin alone (fig. 4); however, it should be noted that during $\mathrm{ADN}$ and $\mathrm{ACH}$ stimulation, $\mathrm{FBF}$ rates were considerably higher than with insulin alone. Thus the 2 conditions are not comparable. ADN's effect in the forearm vasculature is partly nitric oxide-dependent $[13,14]$ and the short half-life $(<10 \mathrm{~s})$ makes it suitable for repeated tests. By using intra-arterial infusion, general sympathetic activation is avoided which otherwise could counteract the vasodilator effect via activation of vasoconstrictor $\alpha$-receptors in the vascular smooth muscle in the arterioles.

In agreement with the similar resistance vessel vascular response in LBW and CON, biomarkers of inflammation and endothelial function (hsCRP, ICAM-1, VCAM1 , homocysteine and vWF) were similar in LBW and CON. Consequently, it can be concluded that the impaired vascular insulin response observed in LBW may 
exist without endothelial damage/dysfunction and lowgrade inflammation. To our knowledge VCAM and ICAM have not been measured in LBW and a matched control group before. Increased homocysteine [36] and vWF [12] concentrations in plasma have been reported previously in 69 boys and girls who were between 8 and 13 years old and had LBW (homocysteine), and in 12 adults with LBW (vWF). The latter finding was not accompanied by an impaired endothelial function [12]. The discrepancy between the present study and the previous studies may be explained by differences in age and study group size.

In summary, we found diminished insulin-mediated FBF and glucose clearance rates in subjects with LBW compared with a well-matched group of CON. The vasodilator responses to $\mathrm{ADN}$ and $\mathrm{ACH}$ and biomarkers of inflammation were not different between the groups. The impaired insulin-mediated increase in bulk flow in
LBW may be due to an impairment of insulin-mediated capillary recruitment in these subjects. The decreased insulin-mediated forearm glucose clearance did not translate into significantly decreased whole-body insulin-mediated glucose uptake in LBW, albeit the M-value was slightly lower in LBW compared with CON.

\section{Acknowledgments}

The support of this study by the Lundbeck Foundation, the Novo Nordic Foundation, the Aase and Ejnar Danielsen Foundation, Vilhelm Pedersen and Wife Grant by recommendation of the Novo Nordisk Foundation and a European Union grant (6th framework LSHM-CT-2004-005272, Exgenesis) is gratefully acknowledged. Regitze Kraunsøe, Jeppe Bach, Thomas Bech and the laboratory at Steno Diabetes Centre are thanked for technical assistance. The metabolic kitchen at Steno Diabetes Hospital is thanked for providing and managing the diet.

\section{References}

1 Hales CN, Barker DJ: Type 2 (non-insulindependent) diabetes mellitus: the thrifty phenotype hypothesis. Diabetologia 1992; 35:595-601.

-2 Jensen CB, Storgaard H, Madsbad S, Richter EA, Vaag AA: Altered skeletal muscle fiber composition and size precede whole-body insulin resistance in young men with low birth weight. J Clin Endocrinol Metab 2007; 92:1530-1534.

-3 Newsome CA, Shiell AW, Fall CH, Phillips DI, Shier R, Law CM: Is birth weight related to later glucose and insulin metabolism? A systematic review. Diabet Med 2003;20:339348.

4 Poulsen P, Vaag A: The intrauterine environment as reflected by birth size and twin and zygosity status influences insulin action and intracellular glucose metabolism in an ageor time-dependent manner. Diabetes 2006; 55:1819-1825.

5 Poulsen P, Wojtaszewski JF, Richter EA, Beck-Nielsen H, Vaag A: Low birth weight and zygosity status is associated with defective muscle glycogen and glycogen synthase regulation in elderly twins. Diabetes 2007; 56:2710-2714.

-6 Alexander BT: Divergent origins of slow fetal growth: relevance to adult cardiovascular disease. Hypertension 2007;50:465-466.

-7 Barker DJ, Gluckman PD, Godfrey KM, Harding JE, Owens JA, Robinson JS: Fetal nutrition and cardiovascular disease in adult life. Lancet 1993;341:938-941.
\$8 Goodfellow J, Bellamy MF, Gorman ST, Brownlee M, Ramsey MW, Lewis MJ, Davies DP, Henderson AH: Endothelial function is impaired in fit young adults of low birth weight. Cardiovasc Res 1998;40:600-606.

9 Hermann TS, Rask-Madsen C, Ihlemann N, Dominguez H, Jensen CB, Storgaard H, Vaag AA, Kober L, Torp-Pedersen C: Normal insulin-stimulated endothelial function and impaired insulin-stimulated muscle glucose uptake in young adults with low birth weight. J Clin Endocrinol Metab 2003;88:12521257.

10 Leeson CP, Whincup PH, Cook DG, Donald AE, Papacosta O, Lucas A, Deanfield JE: Flow-mediated dilation in 9- to 11-year-old children: the influence of intrauterine and childhood factors. Circulation 1997;96: 2233-2238.

11 Leeson CP, Kattenhorn M, Morley R, Lucas A, Deanfield JE: Impact of low birth weight and cardiovascular risk factors on endothelial function in early adult life. Circulation 2001;103:1264-1268.

12 McAllister AS, Atkinson AB, Johnston GD, McCance DR: Relationship of endothelial function to birth weight in humans. Diabetes Care 1999;22:2061-2066.

13 Costa F, Biaggioni I: Role of nitric oxide in adenosine-induced vasodilation in humans. Hypertension 1998;31:1061-1064.

14 Smits P, Williams SB, Lipson DE, Banitt P, Rongen GA, Creager MA: Endothelial release of nitric oxide contributes to the vasodilator effect of adenosine in humans. Circulation 1995;92:2135-2141.
15 Sundell J, Luotolahti M: Association between insulin resistance and reduced coronary vasoreactivity in healthy subjects. Can J Cardiol 2004;20:691-695.

16 Sundell J, Nuutila P, Laine H, Luotolahti M, Kalliokoski K, Raitakari O, Knuuti J: Dosedependent vasodilating effects of insulin on adenosine-stimulated myocardial blood flow. Diabetes 2002;51:1125-1130.

17 Clark MG, Wallis MG, Barrett EJ, Vincent MA, Richards SM, Clerk LH, Rattigan S: Blood flow and muscle metabolism: a focus on insulin action. Am J Physiol Endocrinol Metab 2003;284:E241-E258.

18 Vincent MA, Clerk LH, Lindner JR, Klibanov AL, Clark MG, Rattigan S, Barrett EJ: Microvascular recruitment is an early insulin effect that regulates skeletal muscle glucose uptake in vivo. Diabetes 2004;53:1418-1423.

19 Clark MG, Rattigan S, Barrett EJ: Nutritive blood flow as an essential element supporting muscle anabolism. Curr Opin Clin Nutr Metab Care 2006;9:185-189.

-20 Vincent MA, Clerk LH, Rattigan S, Clark MG, Barrett EJ: Active role for the vasculature in the delivery of insulin to skeletal muscle. Clin Exp Pharmacol Physiol 2005; 32:302-307.

-21 Clerk LH, Vincent MA, Jahn LA, Liu Z, Lindner JR, Barrett EJ: Obesity blunts insulin-mediated microvascular recruitment in human forearm muscle. Diabetes 2006;55: $1436-1442$. 
-22 Laakso M, Edelman SV, Brechtel G, Baron AD: Decreased effect of insulin to stimulate skeletal muscle blood flow in obese man: a novel mechanism for insulin resistance. J Clin Invest 1990;85:1844-1852.

-23 Friedewald WT, Levy RI, Fredrickson DS: Estimation of the concentration of low-density lipoprotein cholesterol in plasma, without use of the preparative ultracentrifuge. Clin Chem 1972;18:499-502.

-24 Cardillo C, Kilcoyne CM, Nambi SS, Cannon RO III, Quon MJ, Panza JA: Vasodilator response to systemic but not to local hyperinsulinemia in the human forearm. Hypertension 1998;32:740-745.

-25 Randriamboavonjy V, Schrader J, Busse R, Fleming I: Insulin induces the release of vasodilator compounds from platelets by a nitric oxide-G kinase-VAMP-3-dependent pathway. J Exp Med 2004;199:347-356.

-26 Baron AD, Clark MG: Role of blood flow in the regulation of muscle glucose uptake. Annu Rev Nutr 1997;17:487-499.
-27 IJzerman RG, van Weissenbruch MM, Voordouw JJ, Yudkin JS, Serne EH, Delemarrevan de Waal HA, Stehouwer CD: The association between birth weight and capillary recruitment is independent of blood pressure and insulin sensitivity: a study in prepubertal children. J Hypertens 2002;20:19571963.

28 Serne EH, Stehouwer CD, ter Maaten JC, ter Wee PM, Donker AJ, Gans RO: Birth weight relates to blood pressure and microvascular function in normal subjects. J Hypertens 2000;18:1421-1427.

29 Goh KL, Shore AC, Quinn M, Tooke JE: Impaired microvascular vasodilatory function in 3-month-old infants of low birth weight. Diabetes Care 2001;24:1102-1107.

30 Jensen CB, Storgaard H, Dela F, Holst JJ, Madsbad S, Vaag AA: Early differential defects of insulin secretion and action in 19 . year-old Caucasian men who had low birth weight. Diabetes 2002;51:1271-1280.

-31 Olsen DB, Sacchetti M, Dela F, Ploug T, Saltin B: Glucose clearance is higher in arm than leg muscle in type 2 diabetes. J Physiol 2005;565:555-562.
32 Sundell J, Laine H, Luotolahti M, Nuutila P, Kalliokoski K, Raitakari O, Knuuti J: Blunted coronary vasoreactivity to insulin is an early alteration in hypertension. J Vasc Res 2003;40:58-67.

33 Curhan GC, Chertow GM, Willett WC, Spiegelman D, Colditz GA, Manson JE, Speizer FE, Stampfer MJ: Birth weight and adult hypertension and obesity in women. Circulation 1996;94:1310-1315.

34 Singhal A, Kattenhorn M, Cole TJ, Deanfield J, Lucas A: Preterm birth, vascular function, and risk factors for atherosclerosis. Lancet 12001;358:1159-1160.

35 Taddei S, Virdis A, Mattei P, Natali A, Ferrannini E, Salvetti A: Effect of insulin on acetylcholine-induced vasodilation in normotensive subjects and patients with essential hypertension. Circulation 1995;92:29112918.

36 Franco MC, Higa EM, D’Almeida V, de Sousa FG, Sawaya AL, Fortes ZB, Sesso R: Homocysteine and nitric oxide are related to blood pressure and vascular function in small-for-gestational-age children. Hypertension 2007;50:396-402. 